\title{
Entre la autobiografía y la universalidad antibelicista: análisis comparatista de $I m$ Westen nichts Neues (Erich M. Remarque, 1929) e Imán (Ramón J. Sender, 1930)
}

\author{
Javier SÁNCHEZ ZAPATERO \\ Universidad de Salamanca \\ zapa@usal.es
}

Recibido: 10 de diciembre de 2010

Aceptado: 15 de marzo de 2011

\section{RESUMEN}

El artículo propone un estudio comparatista de Im Westen nichts Neues (Sin novedad en el frente) e Imán, las obras que sobre su experiencia como combatientes escribieron Erich M. Remarque y Ramón J. Sender en el primer tercio del siglo XX. En el artículo se insiste en la relación de ambas obras con la peripecia biográfica de sus autores, así como en el modo en que se convierten en un alegato antibelicista al denunciar el horror y el absurdo de la guerra a través de la utilización de los mismos tópicos formales y temáticos.

Palabras clave: Literatura de guerra, autobiografía, pacifismo, compromiso, Erich M. Remarque, Ramón J. Sender.

Autobiography and Universal Pacifist Literature: a Comparative Study between Im Westen nichts Neues (Erich M. Remarque, 1929) and Imán (Ramón J. Sender, 1930)

\begin{abstract}
This essay proposes a comparative study of Im Westen nichts Neues and Imán, the books written in the first third of the 20th century by Erich M. Remarque and Ramón J. Sender about their experience in the battlefield.This article emphasizes the links between these two works and their authors' personal experience, as well as the way they both condemn the horror and absurdity of war using the same formal and thematic instruments.
\end{abstract}

Keywords: War Literature, Autobiography, Pacifism, Commitment, Erich M. Remarque, Ramón J. Sender.

SUMARIO: 1. Introducción: El contexto antibelicista. 2. Novelas del yo, novelas autobiográficas. 3. Testimonios de guerra. 4. Alegato antibelicista. 5. El horror bélico. 6. Conclusión: dos obras universales. 


\section{Introducción: El contexto antibelicista}

Publicadas respectivamente en 1929 y 1930, Im Westen nichts Neues (Sin novedad en el frente) e Imán comparten su condición de ejemplos de literatura bélica. A pesar de ocuparse de dos conflictos diferentes -la Primera Guerra Mundial en el primero de los casos y la guerra que enfrentó a España y Marruecos durante el primer cuarto del siglo XX en el segundo- y de haber sido gestadas en distintas culturas y tradiciones lingüísticas, las dos obras coinciden en el mensaje antibelicista que difunden, en la crudeza y minuciosidad con que reflejan la vida cotidiana de los soldados en el frente - marcada por la barbarie, la muerte y la destrucción- y en el hecho de estar basadas en la experiencia personal de sus autores, Erich M. Remarque y Ramón J. Sender. Excombatientes, y, por tanto, testigos y supervivientes del horror bélico, ambos escritores vertebraron a través de sus obras un discurso responsable y consciente de la función social y ejemplarizante que la literatura puede desarrollar. Así, según Fulgencio Castañar (1992: 33), "su carácter social no les hace rechazar la categoría intrínseca que se encierra en una obra de arte, pero posponen lo estético a lo social, el arte al hombre". Trascienden, por lo tanto, el valor meramente estético para convertirse, por encima de todo, en documentos de un tiempo y un acontecimiento concretos y para adquirir una dimensión ética e ideológica asociada al mensaje antibelicista.

Sin novedad en el frente e Imán no fueron los únicos acercamientos de sus autores al tema bélico. Remarque utilizó sus vivencias como soldado en el frente de la Primera Guerra Mundial como base a partir de la que componer sus novelas Der Weg zurück (El camino de vuelta, 1931) y Drei Kameraden (Tres camaradas, 1937) - en las que trataba el difícil proceso de adaptación que hubieron de pasar los soldados que regresaron a sus casas después de permanecer en el frente de batalla-, y dedicó también varias obras de su bibliografía a lo acontecido en Alemania durante la expansión del nazismo y el desarrollo de la Segunda Guerra Mundial. Sender, por su parte, volvió a tratar el asunto de la Guerra de Marruecos en obras como Cabrerizas altas (1966) o Una hoguera en la noche (bajo el signo de Aries) (1980), al tiempo que hizo de la Guerra Civil, en la que también participó como combatiente, tema recurrente y obsesivo de su producción ${ }^{1}$.

Además de no suponer una excepción en la bibliografía de sus autores, Sin novedad en el frente e Imán no fueron una anomalía ni un hito diferencial en el panorama cultural en que nacieron. La obra de Remarque ha de inscribirse dentro del grupo de títulos que, durante la década de 1920 y los primeros años de la de 1930, intentaron reflejar la experiencia bélica a través de una postura de cuestionamiento ante la guerra y los intereses que llevaron a ella ${ }^{2}$. Autores

1 Así lo demuestran títulos como Crónica del alba (1942-1966), El rey y la reina (1947), Los cinco libros de Ariadna (1957) o Réquiem por un campesino español (1960, publicada en 1953 con el título de Mosén Millán).

${ }^{2}$ Junto a esta actitud crítica convivió otra, representada de forma paradigmática por Ernst JÜNGER y su libro de memorias In Stahlgewittern (Tempestades de acero, 1925). Basada también en 
alemanes como Ernst Glaeser -Jahrgang 1902 (Los que teníamos doce años: novela de la guerra, 1928)-, Ludwig Renn -Krieg (Guerra, 1928)-, Georg von der Vring -Soldat Suhren (El soldado Suhren, 1928)-, o Arnold Zweig-Der Streit um den Sergeanten Grischa (El sargento Grischa, 1927)- han de ser incluidos en este corpus ${ }^{3}$, en el que también tendrían cabida escritores de otras nacionalidades y culturas, demostrando con ello el carácter universal de su mensaje pacifista y de su interpretación de la guerra como fenómeno destructor: Henri Barbusse - Le feu ( $E l$ fuego. Diario de un pelotón, 1916)-, Louis-Ferdinand Céline -Voyage au bout de la nuit (Viaje al fin de la noche, 1932)-, John Dos Passos -Three Soldiers (Tres soldados, 1921)-, E. E. Cummings -The Enourmous Room (La habitación enorme, 1932)-, William Faulkner -Soldiers Pay (La paga de los soldados, 1926)-, Ernest Hemingway -A Farewell to Arms (Adiós a las armas, 1929)- o Robert Graves -Goodbye to All That (Adiós a todo eso, 1929)-. Todos los escritores reseñados comparten el hecho de escribir sobre la guerra partiendo de su propia experiencia y de, en consecuencia, haber participado en el conflicto como soldados, voluntarios, enfermeros, corresponsales, etc.

Las novelas de los excombatientes y supervivientes de la Primera Guerra Mundial tuvieron gran éxito en España. La repercusión de Barbusse, Glaeser y, sobre todo, Remarque fue enorme. Sólo en 1930 la editorial Cenit publicó nueve ediciones - de una media de 10.000 ejemplares cada una- de Sin novedad en el frente $^{4}$. Quizá aludiendo a ese éxito, y a la proliferación en todo el continente de las ideas internacionalistas como consecuencia, entre otras cosas, del impacto de la Revolución Rusa, ha de entenderse la publicación de obras como la de Sender sobre la Guerra de Marruecos, eslabón de una cadena en la que también han de situarse títulos como El blocao (1928), de José Díaz Fernández, o La barbarie organizada (1931), de Fermín Galán. Junto a este nivel universal y ejemplar, existiría en Imán -y en el resto de novelas españolas dedicadas al tema- otro caracterizado por su carácter particular. Y es que, además de ser un ejemplo de literatura bélica, la obra de Sender supone también una reflexión sobre la situación

sus vivencias como combatiente alemán en la Gran Guerra, la obra de Jünger interpreta el conflicto bélico como una experiencia de iniciación que provoca el crecimiento personal y moral de quien participa en ella, reflexión sobre la que profundizaría en títulos como Der Kampf als inneres Erlebnis (El combate como vivencia interior, 1922), Feuer und Blut (Fuego y sangre, 1925) o Das Wäldchen 125 (La arboleda 125, 1925).

${ }^{3}$ Evidentemente, la importancia que tuvo la guerra, así como sus consecuencias, en la sociedad alemana hizo que fueran muchos los autores que, sin haber participado directamente en el conflicto, trataran el tema en sus creaciones. Así lo evidencian, por ejemplo, casos como los de Reinhard GOERING y Seeschlacht (Batalla Naval, 1917), Bertold BRECHT y Trommeln in der Nacht (Tambores en la noche, 1919), y Joseph Rотн у Die Flucht ohne Ende (Fuga sin fin, 1927). Según Isabel HeRnÁNDEZ y Manuel MALDONAdo (2003: 186), el impacto que la Primera Guerra Mundial provocó en la literatura alemana se debió, fundamentalmente, a que "ante el conflicto [...] el artista se plantea su responsabilidad moral y social [...] ante la transformación del mundo conocido".

${ }^{4}$ El éxito de la novela de Remarque en todo el mundo conllevó su adaptación al cine en 1930. La película, de título homónimo, fue dirigida por el estadounidense Lewis Milestone. Varias décadas más tarde, en 1979, Delbert Mann realizó un remake para ser emitido en televisión. 
social y política de la España de la época. Incluso su origen puede interpretarse como una lógica consecuencia a la posición de la opinión pública, pues, como señaló José Ortega y Gasset (apud Castañar 1992: 144), tras el desastre colonial de 1898, "la voluntad colectiva de España, con rara e inconcebible unanimidad, adoptó la inquebrantable resolución de no entrar en empresas bélicas". Así lo ponen también de manifiesto sucesos como los de la Semana Trágica de Barcelona de 1909 que, si bien estaba motivada por el descontento general de ciertos sectores de la sociedad con la situación política del país, tuvo como desencadenante la cuestión colonial y la marcha forzosa de miles de españoles al frente marroquí. El reflejo de la realidad española también explica que el problema del colonialismo sea de uno de los temas de discusión constantes entre los diversos personajes que aparecen en la novela. Según Carrasco (2000: 77), de hecho, Sender es un autor "que está contra el Protectorado, aunque nunca haga referencia a ello, sino que se intuye en su amargo escrito [y] es ante todo sensible a la situación de sufrimiento de las tropas españolas y por eso se vuelve claramente antibelicista".

\section{Novelas del yo, novelas autobiográficas}

Un primer acercamiento formal a Sin novedad en el frente e Imán conlleva su adscripción al género novelesco. De hecho, como novelas fueron presentadas al público por su aparato paratextual en el momento de su publicación. Sin embargo, aunque sus personajes principales -Paul Bäumer y Viance, respectivamente ${ }^{5}$ - son criaturas de ficción que no se identifican nominalmente con sus creadores ni con cualquier otro individuo cuya existencia haya podido ser verificada -aunque sí con la instancia narrativa en el primero de los casos-, los hechos que protagonizan se refieren a acontecimientos concretos sucedidos en el mundo real y, por tanto, susceptibles de ser comprobados empíricamente por el lector. Hay, en consecuencia, una correspondencia entre lo relatado y la realidad que impide efectuar una lectura análoga a la que se ejecuta sobre los textos de ficción. Así lo ponen de manifiesto ambos autores en el prólogo con que presentan sus obras. Mientras Remarque asume la veracidad de lo narrado en su libro al afirmar en su nota introductoria que su intención fue mostrar una generación destruida por la guerra ${ }^{6}$, Sender (1998: 5)

\footnotetext{
${ }^{5}$ En su trabajo comparatista sobre el libro, Charles OLSTAD (1977: 135) ha expuesto algunas de las diferencias existentes entre los dos personajes, centrándose tanto en su origen social "Remarque's Paul Bäumer is of the urban lower middle class in a small city; his mother, who has a small apartament there, sends letters and parcels to her son at the front. Viance (he is known only by this name) is the rural lower class; his father was an Aragonese sharecropper of the most destitute"como en su forma de comportarse y relacionarse con los demás, insistiendo en el compañerismo del primero y en el carácter solitario del segundo. Semejantes distinciones refuerzan el mensaje universal que ambas novelas desean transmitir, pues evidencian cómo la guerra afecta por igual a todos los individuos, por muy diferentes que éstos sean entre sí.

6 "Dieses Buch soll weder eine Anklage noch ein Bekenntnis sein. Es soll nur den Versuch machen, über eine Generation zu berichten, die vom Kriege zerstört wurde - auch wenn sie seinen
} 
explica que en la composición de su obra "la imaginación ha tenido bien poco nada, en verdad- que hacer" y que Imán "trata de contar la tragedia de Marruecos como pudo verla un soldado cualquiera".

Al vincular semejante declaración de intenciones con la peripecia biográfica de los escritores, marcada por su experiencia como combatientes, se evidencia la imposibilidad de leer las obras ejecutando el pacto narrativo que induce a la suspensión de la credibilidad. No parece haber invención en lo relatado, sino que todo parece ser un expediente de realidad circunscrito geográfica y temporalmente a lo experimentado por los autores en el frente de batalla. No obstante, a pesar de haber sido concebidas con la intención de relatar experiencias vividas, resulta sumamente problemático defender el carácter autobiográfico de las obras, puesto que no se dan en ellas particularidades esenciales del género como son la correspondencia entre autor, narrador y personaje -aunque hay una explícita identificación, la ausencia de correspondencia nominal impide hablar de igualdad entre las tres instancias.

La confusión que genera tal ambigüedad, que impide catalogar a las obras como novelas o como autobiografias, puede ser resuelta aludiendo a la teoría de Manuel Alberca (2007: 61-62), para quien existiría un tercer modelo de lectura, situado entre el narrativo y el referencial y ejecutado a través de lo que se ha denominado como "pacto ambiguo" -y, por tanto, "ficticio y verdadero simultáneamente" (Alberca 1996: 180) ${ }^{7}$ - Alberca ha llamado a estas obras, que no pueden ser leídas como ficción pero tampoco como expediente de realidad, "novelas del yo", evidenciando así tanto su apariencia formal de novela como su relación con el género autobiográfico y con el relato de una vida real:

[Las novelas del yo] mantienen una relación ambigua con respecto a lo real y a lo vivido, pero los autores, al proponer el estatuto de ficción para ellas, les confieren a éstas un carácter textual. [...] No es posible comprenderlas en su especificidad sin considerar las relaciones extratextuales del relato ni tener en cuenta su lado biográfico, pues estos relatos acaban por dibujar una determinada figura del autor, y esa figura remite al individuo que reconocemos en el escritor.

Aplicar la terminología de Alberca al análisis de Sin novedad en el frente e Imán conllevaría catalogar ambas obras como novelas del yo $-\mathrm{y}$, en concreto,

Granaten entkam" (REMARQUE 1974: 5) ["Este libro no representa ni una denuncia ni una confesión. Pretende únicamente mostrar una generación que fue destruida por la Guerra, aunque escapara a las granadas" (REMARQUE 2005: 7)].

7 Análogo al concepto de "pacto ambiguo" es el de "lectura cuasipragmática", creado por Karlheinz STIERLE (1987: 104) y cuya principal característica sería la de intentar provocar en el receptor una ilusión de realidad. Esta modalidad lectora se situaría entre las dos tipologías clásicas, la pragmática y la no pragmática o ficcional, diferenciadas por la posibilidad de someterse al criterio de veracidad. A través de la lectura cuasipragmática, un texto de fícción puede ser interpretado como si fuera real, pero teniendo siempre en cuenta que, por su carácter literario, es autorreferencial y, por tanto, todo lo que en él se cuente, aunque parta de una experiencia real, existe sólo porque aparece en el papel. 
como "novelas autobiográficas" ${ }^{\prime}$, pues hay en lo narrado en ellas por los autores un sustrato de realidad que impide tomar lo leído por ficción, por mucho que así sean presentadas formalmente ante los lectores. En el fondo, lo que demuestran textos como de Remarque y Sender es que la proyección de las vivencias de un escritor, e incluso de su propia personalidad, no es una característica exclusiva de un tipo particular de relatos o géneros -y más teniendo en cuenta que es imposible definir formalmente las características que habrían de tener esos relatos, puesto que lo único que diferencia a los textos referenciales de los ficcionales es la mirada que sobre ellos proyecta el lector, dispuesto a tomar los primeros por expedientes de realidad y los segundos por invención-. De hecho, las formas en las que la vida de un creador puede infiltrarse en su obra son infinitas, pues, como ha señalado Elisa Martínez Garrido, "todo hecho de escritura responde a una práctica existencial traducida en lenguaje" (Martínez Garrido 1986: 272). Francisco Ayala ha incidido también en esa idea al señalar que "el literato produce a partir de su personal genio; pero este impulso propio requiere ser realizado sobre la base de unos materiales de experiencia" (Ayala 1958: 22). Por su parte, José Romera Castilla (1981: 13) ha definido al escritor como el "signo referencial de su escritura". La identificación entre lo escrito y lo vivido cobra especial relevancia en lo que Martínez Garrido (1986: 273) ha definido como "relatos especulares":

Un relato especular es un relato sobrecargado semánticamente; es decir, un relato cuyo enunciado, que soporta la reflexividad, funciona en dos niveles: como relato en sí mismo y como reflexión de otra realidad segunda que deja traslucir. [...] En consecuencia, para deducir el doble sentido, para poder descifrar las identificaciones y para poder descifrar la segunda lectura, hay que reconocer la primera.

${ }^{8}$ Según Manuel Alberca (2007: 92 y ss.), dentro de las "novelas del yo" se pueden distinguir entre las novelas autobiográficas, las autobiografías ficticias y las autoficciones. Las diferencias entre las tres categorías vendrían determinadas por la combinación de dos criterios: identidad nominal y propuesta de lectura. Así, las novelas autobiográficas no implican correspondencia entre autor, narrador y personaje -sí en ocasiones entre las dos últimas instancias-y conllevan lo que se ha dado en denominar "autobiografismo escondido", pues intentan ocultar las huellas autobiográficas en el desarrollo de un discurso ficcional. En las autobiografías ficticias tampoco se cumplimentaría el principio de identidad pero, al contrario que las anteriores, la propuesta de lectura iría encaminada hacia un "autobiografismo simulado", ya que tienen la pretensión de que el lector tome como real un texto ficticio, como puede observarse en la picaresca o en el Bildungsroman, cuyas características formales son análogas a las de la autobiografía. Las diferencias entre estas dos manifestaciones de las "novelas del yo" podrían determinarse en el hecho de que mientras la primera induce a leer como ficticios acontecimientos que acontecieron y de los fue testigo el autor, la segunda intenta hacer pasar por real algo que jamás sucedió. Por último, la autoficción -neologismo creado por Serge Doubrosky en 1970- participa tanto de la autobiografía como de los textos ficcionales: su característica esencial es la de presentar una identidad entre autor, narrador y personaje, pero relatar una historia cuya correspondencia con lo realidad y con lo vivido no es segura, con lo que cumple el principio de identidad típico de los textos autobiográficos pero no el de veracidad, generando así ambigüedad y confusión en el receptor. 
La existencia de este tipo de textos ha llevado a Nora Catelli (1991: 11) a la creación del término "espacio autobiográfico", que no implica someter lo leído a los antes mencionados principios de identidad y veracidad, sino, simplemente, admitir que pueden existir rastros que remitan al sujeto creador en diversos y heterogéneos textos. Así, el espacio autobiográfico sería el "lugar donde se da cabida al relato de una vida desde la mentira" y se caracterizaría por cifrar la relación entre el autor y el texto en términos de analogía. Semejante al concepto de espacio autobiográfico sería el de "pacto fantasmático", creado por Lejeune (2004) y referido a las novelas que, al remitir a aspectos de la identidad de quien las crea y convertirse en "fantasmas" reveladores de la vida de un individuo, admiten una lectura que va más allá de la ficción. César Nicolás (2004: 512), por su parte, ha advertido del "entrecruzamiento constante" que se produce entre los textos referenciales y los ficcionales, al ser sus diferencias sólo una cuestión de intencionalidad y convenciones lectoras. Asimismo, para Francisco Javier Hernández (1999: 83) las relaciones entre la novela y la autobiografía están marcadas por "la existencia de vasos comunicantes" que las conectan e interaccionan. Mientras, Romera Castillo (1981: 13) ha afirmado que las fronteras entre ambos tipos de textos se hallan inmersas en un constante proceso de difuminación de fronteras, pues "la literatura intimista [...] se caracteriza, ante todo, por ser una literatura referencial del yo existencial, asumido, con mayor o menor nitidez, por el autor de la escritura; frente a la literatura que podríamos llamar ficticia, en la que el yo, sin referente específico, no es asumido existencialmente por nadie en concreto".

De todo el andamiaje teórico expuesto se deduce que Sin novedad en el frente e Imán -al igual que otras obras similares, como pueden ser El fuego, de Barbusse, o El blocao, de José Fernández Díaz, combatientes ambos en los mismos conflictos bélicos que Remarque y Sender- son susceptibles de ser catalogadas como "novelas del yo" -y, más concretamente, como "novelas autobiográficas"-, como "relatos especulares", como muestras del "espacio autobiográfico" o como manifestaciones textuales de "pacto fantasmático". La diferencia nominal no impide que, en el fondo, todas las categorías señaladas incidan en las mismas características y que, en consecuencia, todas se refieran a textos que relatan hechos referenciales, acaecidos en el mundo real, protagonizados y experimentados por sus autores, susceptibles de ser verificados y comprobados empíricamente, que, sin embargo, son presentados como si de una obra de ficción se tratase.

\section{Testimonios de guerra}

Resulta de suma importancia tener en cuenta el carácter de expediente de realidad que tienen los hechos relatados en Sin novedad en el frente y en Imán, pues, como ya ha sido apuntado, una de las intenciones con las que sus autores abordaron su composición fue la de transmitir la realidad de una experiencia concreta dotada de unos elevados niveles de intensidad y dimensión traumática: 
la guerra. De hecho, podría decirse que tanto Erich M. Remarque como Ramón J. Sender disponen de la legitimidad necesaria para escribir sobre el conflicto precisamente por su condición de testigos y supervivientes, que les capacita para dar a conocer a los demás los acontecimientos y experiencias con que entraron en contacto en el frente de batalla. Es decir, la visión que en estas obras se da de la guerra parte de los recuerdos de la experiencia personal de los autores -no se cuenta, por tanto, la guerra, sino "su" guerra- y precisamente por eso son perdonables los errores cometidos en el intento de recrear la realidad. El deseo de alcanzar la verdad de los acontecimientos pesa más que los inevitables fallos que se puedan incurrir en el proceso de transmisión, entre otras cosas porque el mero intento de los autores implica una postura ante el texto que, trascendiendo lo meramente estético, se dota de dimensiones éticas, ideológicas y políticas.

Una de las razones que llevaron tanto a Remarque como a Sender a testimoniar sobre su experiencia como soldados fue la falta de convergencia entre su memoria personal $-\mathrm{y}$, por extensión, la de la gran mayoría de combatientes en la guerra- y la memoria social que los medios de comunicación y los mensajes oficiales intentaron instalar en la ciudadanía de Alemania y de España durante el desarrollo de, respectivamente, la Primera Guerra Mundial y la Guerra de Marruecos. En ambos casos, lo que se intentó desde el poder fue desarrollar una intensa labor de comunicación destinada a infundir ánimo y confianza a sus sociedades ante el conflicto, consistente en mentir sobre el desarrollo de las hostilidades, minimizar el número de bajas, exagerar sobre los daños infringidos al enemigo y, en general, obviar la destrucción que el combate estaba produciendo. Frente a esa interpretación de la historia, difundida a través de los periódicos, de determinados líderes de opinión y del aparato propagandístico, diversos escritores-soldado van a intentar hacer de sus narraciones un instrumento capacitado para dar voz a quienes son silenciados por las versiones oficiales y para iluminar aquellos acontecimientos de los que jamás nadie se ocupará. De ahí que sea tan importante tener en cuenta la cercanía del año de publicación de las obras respecto al de los hechos que se refieren, evidenciando con ello la intención de sus autores de influir en la ciudadanía y ofrecerles la visión del conflicto que se considera verdadera ${ }^{9}$.

En determinados pasajes de las obras, los autores explicitan su intención de luchar contra la interpretación que de la guerra están transmitiendo los medios de comunicación, tal y como ocurre en el fragmento de Sin novedad en el frente en el que el autor explica cómo el único modo de soportar la convivencia diaria con la muerte está en el intento de banalizar lo sucedido en las trincheras:

${ }^{9}$ Este interés hace que una obra como La ruta, de Arturo Barea, de características textuales y temáticas casi análogas a la de Imán -pues también está vertebrada por las experiencias que como combatientes vivió en Marruecos Barea-, merezca un análisis diferente. Al ser publicada en la década de 1950, carece de la intención pragmática de la obra de Sender. 
Das Grauen der Front versinkt, wenn wir ihm den Rücken kehren, wir gehen ihm mit gemeinen und grimmigen Witzen zuleibe; wenn jemand stirbt, dann heißt es, daß er den Arsch zugekniffen hat, und so reden wir über alles, das rettet uns vor dem Verrücktwerden, solange wir es so nehmen, leisten wir Widerstand.

Aber wir vergessen nicht! Was in den Kriegszeitungen steht über den goldenen Humor der Truppen, die bereits Tänzchen arrangieren, wenn sie kaum aus dem Trommelfeuer zurück sind, ist großer Quatsch. Wir tun das nicht, weil wir Humor haben, sondern wir haben Humor, weil wir sonst kaputt gehen ${ }^{10}$ (Remarque 1974: 131).

La narración gloriosa de las grandes batallas va a ser sustituida en las dos novelas analizadas en este artículo por el relato de la intrahistoria bélica. De hecho, lo que en ellas se va a relatar es cómo afecta a los combatientes su participación en la guerra y de qué modo la entrada en contacto con la muerte y el horror va a cambiar para siempre sus vidas. Las pequeñas tragedias que esconde un acontecimiento tan monstruoso como la guerra, habitualmente silenciadas y omitidas de los imaginarios sociales, van a ocupar el primer plano de sus narraciones, que van a dotarse así de lo que algunos autores han denominado "carácter democrático" (Aguado 2004: 114). Al dar recursos lingüísticos a los marginados de la historia -los soldados que sufren en las trincheras, los muertos que caen en combate, los habitantes de las ciudades bombardeadas acostumbrados a vivir con el miedo...- para que su discurso pueda hacerse oír, estas obras ayudan a la creación de una esfera pública carente de verdades únicas. Sin novedad en el frente e Imán son, por lo tanto, intentos de transmitir a la ciudadanía la verdad de lo sucedido. O, al menos, la verdad de lo sucedido en el limitado ámbito de percepción de sus autores. En la literatura bélica contemporánea no existen explicaciones globales del conflicto, ni visiones cenitales que permitan dar sentido a todos los acontecimientos. Llegando a dudar de que éstas existan, lo que los autores se limitan a mostrar es la cruda realidad por ellos vivida. Frente a las informaciones de los periódicos y a sus continuas referencias a victorias, avances militares y castigos al enemigo, las obras aquí estudiadas se limitan a mostrar la cotidianeidad de la guerra, llena de polvo, sangre y sufrimiento.

Junto a su propia experiencia, los autores disponen de una tradición de literatura bélica para vertebrar sus relatos. Si por un lado se va a prescindir de los modelos clásicos centrados en el valor y en el heroísmo, por otro se van a tomar como referente novelas como La Chartreuse de Parme - La cartuja de Parma (1839), de Stendhal-, Война и мир, "Voina i mir" -Guerra y paz (1969), de Lev

${ }^{10}$ El horror del frente se hunde en nuestro interior en cuanto le volvemos la espalda; lo acuciamos con bromas innobles y feroces. Cuando alguien muere decimos que "ha encogido el culo" y hablamos en ese tono de todas las cosas. Eso nos libra de volvernos locos. Mientras nos lo tomamos así, ofrecemos resistencia.

¡Pero no olvidamos! Lo que cuentan los periódicos de guerra a propósito del buen humor de los soldados, que organizan bailes en cuanto dejan el frente, es una sublime tontería. No lo hacemos porque estemos de buen humor, sino que estamos de buen humor porque de otro modo reventaríamos (REMARQUE 2005: 131). 
Tosltoi- o The red badge of courage -La roja insignia del valor (1895), de Stephen Crane-, caracterizadas por presentar en el frente a personajes jóvenes e idealistas, tan deseosos de conocer la épica de la batalla como decepcionados por no encontrar en ella nada más que caos, destrucción y muerte. Así, es sintomático que, por ejemplo, el protagonismo de las novelas pacifistas suela otorgarse a personajes jóvenes que, además de mantener similares características a las de los autores en el momento de experimentar los hechos por ellos narrados, presentan ciertas concomitancias con los modelos antiheroicos típicos de la tradición iniciada por Stendhal, Tolstoi y Crane. No hay, sin embargo, en los personajes prototípicos de la literatura bélica del siglo XX rastro alguno de idealismo. Así lo expresa de forma paradigmática un pasaje de Imán en el que el narrador muestra la trágica ironía que suponía ensalzar como modelos a seguir a quienes vivían en condiciones infrahumanas y habían de convivir a diario con la muerte. Con su crítica no sólo muestra Sender que la vida militar es muy diferente a las ideas estereotipadas que la cultura occidental acostumbra a mostrar sobre el tema, sino también y sobre todo que su imagen real distaba mucho de la que estaba siendo ofrecida en España: "Nosotros somos lo que en la prensa y las escuelas llaman héroes: Llevar sesos de un compañero en la alpargata, criar piojos y beber orines, eso es ser héroes. Yo soy un héroe" (Sender 1998: 51).

La conversión del tradicional héroe en un personaje profundamente antiheroico no hace sino poner de manifiesto la decadencia de una sociedad en trances de destrucción por la perversión de las clases dominantes. En la obra de Remarque, esa desorientación se acompaña de una crítica a las generaciones anteriores, responsables del conflicto:

Sie sollten uns Achtzehnjährigen Vermittler und Führer zur Welt des Erwachsenseins werden, zur Welt der Arbeit, der Pflicht, der Kultur und des Fortschritts, zur Zukunft. Wir verspotteten sie manchmal und spielten ihnen kleine Streiche, aber im Grunde glaubten wir ihnen. Mit dem Begriff der Autorität, dessen Träger sie waren, verband sich in unseren Gedanken größere Einsicht und menschlicheres Wissen. Doch der erste Tote, den wir sahen, zertrümmerte diese Überzeugung. Wir mußten erkennen, daß unser Alter ehrlicher war als das ihre; sie hatten vor uns nur die Phrase und die Geschicklichkeit voraus. Dar erste Trommelfeuer zeigte uns unseren Irrtum, und unter ihm stürzte die Weltanschauung zusammen, die sie uns gelehrt hatten.

Während sie noch schrieben und redeten, sahen wir Lazarette und Sterbende; - während sie dens Dienst am Staate als das Größte bezeichneten, wußten wir bereits, daß die Todesangst stärker ist. Wir wurden darum keine Meuterer, keine Deserteure, keine Feiglinge - alle diese Ausdrücke waren ihnen ja so leicht zur Hand -, wir liebten unsere Heimat genauso wie sie, und wir gingen bei jedem Angriff mutig vor; aber wir unterschieden jetzt, wir hatten mit einem Male sehen gelernt. Und wir sahen, daß nichts von ihrer Welt übrig blieb (Remarque 1974: 17) ${ }^{11}$.

${ }^{11}$ Deberían haber sido para nosotros, jóvenes de dieciocho años, mediadores y guías que nos condujeran a la vida adulta, al mundo del trabajo, del deber, de la cultura y del progreso, hacia el porvenir. A veces nos burlábamos de ellos y les jugábamos alguna trastada, pero en el fondo 
Tal y como se puede detectar en esta cita, es común a las dos obras el hecho de erigir a sus protagonistas y narradores en portavoces del colectivo de soldados del que forman parte. Mientras, como ya ha sido apuntado, en el prólogo de Sin novedad en el frente se explicita su voluntad de "manifiesto generacional", en la nota introductoria que acompañó la primera edición de Imán se deja claro que la visión del narrador de la obra "trata de contar la tragedia de Marruecos como pudo verla un soldado cualquiera" y que en su protagonista "se puede comprobar la mayor parte de los soldados y campesinos que fueron allá sin ideas propias, obedeciendo un impulso ajeno y admirando a los héroes que salen retratados en los periódicos" (Sender 1998: 5). También incide Sender (1998: 5) en que "cualquiera de los doscientos mil soldados que desde 1920 o 1925 desfilaron por allá podría firmar" un libro como el suyo. No en vano, el valor de representación de Viance, el protagonista, es puesto de manifiesto en varias ocasiones, como cuando se señala que "un soldado es igual a otro y a otro" (Sender 1998: 114) o cuando, tras hacer el protagonista un resumen de su vida al narrador, éste afirma que existirían muchas "historias parecidas" (Sender 1998: 75) si se escuchase al resto de los miembros del ejército. Lo que se quiere evidenciar con semejantes palabras es que la de los protagonistas de la novela $-y$, por extensión, la de los autores en la que se basa- no es una historia excepcional. La peripecia que narran Sin novedad en el frente e Imán es análoga a la que hubieron de sufrir miles de combatientes en los frentes de la Primera Guerra Mundial y la Guerra de Marruecos, e incluso en los de cualquier conflicto bélico.

\section{Alegato antibelicista}

Ambas obras muestran a los combatientes como individuos alejados de los intereses por los que se estaba peleando en el campo de batalla, con lo que logran vertebrar un discurso antibelicista basado en la artificiosidad de la guerra, concebida como un fenómeno absurdo capaz de conducir hasta la lucha a muerte a jóvenes incapaces de entender el odio que han de sentir hacia su adversario. La penetración

teníamos fe en ellos. La misma noción de la autoridad que representaban les otorgaba a nuestros ojos mucha más perspicacia y sentido común. Pero el primero de nosotros que murió echó por los suelos esa convicción. Tuvimos que reconocer que nuestra generación era mucho más leal que la suya; no tenían más ventajas respecto a nosotros que las palabras vanas y la habilidad. El primer bombardeo nos reveló nuestro error, y con él se derrumbó la visión del mundo que nos habían enseñado.

Mientas ellos seguían escribiendo y discurseando, nosotros veíamos ambulancias y moribundos; mientras ellos proclamaban como sublime el servicio al Estado, nosotros sabíamos ya que el miedo a la muerte es mucho más intenso. Por eso no nos convertimos en rebeldes, ni en desertores ni en cobardes -ello se servían de esas expresiones con gran facilidad; amábamos a nuestra patria tanto como ellos, y nos aprestábamos al combate con coraje; pero ahora teníamos capacidad de discernimiento, de improviso habíamos aprendido a ver y vimos que no quedaba ni rastro de su mundo (REMARQUE 2005: 19). 
de las ideas internacionalistas en el cuerpo intelectual del primer tercio del siglo XX ayudó a desarrollar esta posición pacifista, basada en la hermandad de los seres humanos por encima de cualquier tipo de división cultural artificial -en el caso de la guerra, la pertenencia a una determinada patria-. En Sin novedad en el frente, por ejemplo, apenas hay referencias sobre la identidad de los bandos en combate y la primera referencia nacionalista -"Wir erkennen die verzerrten Gesichter, die flachen Helme, es sind Franzosen" ${ }^{\prime 2}$ (Remarque 1974: 107)- no aparece hasta el capítulo sexto de los doce de que consta la novela. Su autor describe con minuciosidad y realismo el horror del combate, la tensa angustia de la retaguardia y las precarias condiciones en las que permanecen los soldados sin referencias localistas, lo que permite trascender su visión a todas las guerras y a todos los frentes. Se hace hincapié continuamente en lo indiferente que la guerra -vista como un asunto de "alta política" - resulta para los combatientes, muchas veces obreros más cercanos a la sensibilidad e intereses de los soldados del bando contrario que a sus propios cabecillas. Por eso se insiste continuamente en la descripción de aspectos materiales como los uniformes para ejemplificar que, sin ellos, no hay diferencias entre los soldados o se identifica la guerra exclusivamente con intereses que en nada afectan a los combatientes:

Er sich erkundigt, wie eigentlich ein Krieg entstehe.

"Meistens so, daß ein Land ein anderes schwer beleidigt" [...]

"Ein Land? Das verstehe ich nicht. Ein Berg in Deustchland kann doch einen Berg in Frankreich nicht beleidigen. Oder ein Fluß oder ein Wald oder ein Weizenfeld" [...]

"Es ist doch das Volk als Gesamtheit, also der Staat" [...]

"Staat, Staat [...] Feldgendarmen, Polizei, Steuer, das ist euer Staat. Wenn du damit zu tun hast, danke schön" [...]

"Das stimmt [...] Staat und Heimat, da ist wahrhaftig ein Unterschied"

"Aber sie gehören doch zusammen [...]. Eine Heimat ohne Staat gibt es nicht"

"Richtig, aber bedenk doch mal, daß wir fast alle einfache Leute sind. Und in Frankreich sind die meisten Menschen doch auch Arbeiter, Handwerker oder kleine Beamte. Weshalb soll nun wohl ein französischer Schlosser oder Schuhmacher uns angreifen wollen? Nein, das sind nur die Regierungen. Ich habe nie einen Franzosen gesehen, bevor ich hierherkam, und den meisten Franzosen wird es ähnlich mit uns gehen. Die sind ebensowenig gefragt wie wir"'13 (Remarque 1974: 185-186).

12 "Reconocemos los rostros crispados, los cascos planos: son franceses" (REMARQUE 2005: 107).

13 "Ahora quiere saber cómo empieza una guerra.

- Generalmente porque un país ofende gravemente a otro. [...]

- ¿Un país? No lo entiendo. Una montaña alemana no puede ofender a una montaña francesa. Ni un río, ni un bosque, ni un campo de trigo... [...]

- Se refiere al pueblo en conjunto, es decir, al Estado. [...]

- El Estado, el Estado... Guardia rural, policía impuestos... eso es vuestro Estado. Si vosotros tenéis algo que ver con todo eso, yo no. [...]

- Tienes razón. Entre el Estado y la patria hay algunas diferencias [...]

- Pero se corresponden mutuamente [...]. No existe una patria sin Estado. 
Del mismo modo, en Imán se ironiza sobre el verdadero significado del término "patria" para exponer lo alejados que están los soldados que han de combatir de las razones causantes del conflicto bélico en el que se encuentran inmersos:

¿Qué habremos hecho pa [sic] que nos metan en este tiberio? En España nadie sabe lo que aquí pasa. De vez en cuando dicen los periódicos: "nuestros soldados mueren en Africa", pa [sic] molestar al Gobierno, pero el pueblo y los ministros ya se han acostumbrado. ¿Bueno, y qué? Aquello está lejos, y en todo caso es la defensa de la patria. Oye tú, muchacho: ¿Sabes qué es la patria? [...] La patria no es más que las acciones del accionista (Sender 1998: 121).

La crítica a la guerra viene determinada, entre otros motivos, por el hecho de que ambos autores conocieron, en su condición de combatientes, el horror de la guerra y son, por tanto, conscientes de su poder aniquilador, capaz de transformar en bestias asesinas incluso a los seres más ingenuos e inocentes. Así se evidencia en una pasaje de la obra de Remarque (1975: 195) en el que se relata cómo, después de atacar a un enemigo - "ich stoße rasend zu und fühle nur, wie der Körper zuckt und dann weich wird und zusammensackt" ${ }_{14-}$, el protagonista y narrador observa la agonía del soldado moribundo y, tras ser consciente de lo sucedido, se dirige a él15:

- De acuerdo, pero piensa que la mayoría de nosotros somos gente [alemana] sencilla. Y también en Francia la mayoría son obreros, artesanos o pequeños empleados. ¿Cómo puede querer atacarnos un zapatero o un cerrajero francés? No, son únicamente los gobiernos. Antes de venir aquí, yo no había visto nunca a un francés, y a la mayoría de franceses les debe suceder lo mismo con nosotros. A ellos tampoco les han pedido su opinión" (REMARQUE 2005: 185-186).

14 "Apuñalo con furia y siento únicamente como ese cuerpo se estremece y cae con todo su peso" (REMARQUE 2005: 196).

${ }^{15}$ Los procesos bélicos contemporáneos se han caracterizado, entre otras cosas, por la puesta en práctica de ofensivas ejecutadas a distancia. Gracias a los avances técnicos, durante todo el siglo XX se perfeccionaron los bombardeos aéreos, los lanzamientos de misiles o el uso de granadas de mano u otros artefactos explosivos. Su utilización se combinó con los tradicionales combates cuerpo a cuerpo, que quedaron relegados a un segundo plano y se reservaron para determinados momentos de la batalla -como el que se expone en novela de Remarque-. La proliferación de los nuevos ataques conlleva cierta indiferencia moral en su ejecutor, provocada por la distancia temporal y espacial que en ellos se produce entre víctima y verdugo. Esa indiferencia es análoga al desinterés que la gente acostumbra a tener por todo aquello que suceda fuera de los límites de su comunidad. La atención que, casi de forma innata, muestran los hombres para "saber lo que pasa más allá de la experiencia inmediata" (GomIS 1991: 185) está condicionada por los criterios de actualidad-escasa distancia temporal-y de proximidad -escasa distancia espacial-. La cercanía subraya la condición humana de la víctima, que en los ataques a distancia es vista con cierta abstracción, como si simplemente fuera un elemento de una estadística o un cómputo que reflejase las bajas del enemigo. Asimismo, la implicación emocional que supone ver el rostro del contrario, luchar con él cuerpo a cuerpo u observar sus últimas muecas antes de morir conlleva la preocupación y el sentimiento de culpa. Tales sensaciones refuerzan la idea de confusión que los soldados acostumbran a tener durante su estancia en el frente y les llevan a plantearse cuáles son las razones que les han llevado hasta allí y que les impulsan a matar a los miembros del otro bando. 
Kamerad, ich wollte dich nicht töten. Sprängst du noch einmal hier hinein, ich täte es nicht, wenn auch du vernünftig wärest [...]. Jetzt sehe ich erst, daß du ein Mensch bist wie ich. Ich habe gedacht an deine Handgranaten, an dein Bajonett und deine Waffen, jetzt sehe ich deine Frau und dein Gesicht und das Gemeinsame.Vergib mir, Kamerad, wie konntest du mein Feind sein. Wenn wir diese Waffen und diese Uniform fortwerfen, könntest du ebenso mein Bruder. [...] Aber wenn ich davonkomme, Kamerad, will ich kämpfen gegen dieses, das uns beide zerschlug: dir das Leben -und mir? Auch das Leben ${ }^{16}$ (Remarque 1974: 201 y 204).

Tal y como demuestra este pasaje de Sin novedad en el frente, las experiencias de muerte, sufrimiento y deshumanización se convierten en vivencias igualadoras que trascienden cualquier diferencia derivada de la nacionalidad, la raza, la cultura o la situación económica. Por tanto, el sustrato común del dolor es el germen de los sentimientos de hermandad pacifista que transmiten estas novelas. La guerra afecta a todos por igual. Entrar en contacto con sus miserias afecta a todos los que en ella participan, modificando para siempre sus vidas en los niveles físico, psíquico y moral. Tanto Remarque como Sender convivieron el tiempo que estuvieron combatiendo con la muerte y la destrucción, así como con la capacidad alienadora de la experiencia bélica, capaz de marcar de forma traumática para siempre a quien la sufre. Por eso el narrador homodiegético de Sin novedad en el frente manifiesta en una de sus reflexiones las consecuencias que para el proceso de desarrollo de los soldados ha tenido la vida militar y la cotidiana convivencia con el horror:

Heute würden wir in der Landschaft unserer Jugend umhergehen wie Reisende. Wir sind verbrannt von Tatsachen, wir kennen Unterschiede wie Händler und Notwendigkeiten wie Schlächter. Wir sind nicht mehr unbekümmert - wir sind fürchterlich gleichgültig. Wir würden da sein; aber würden wir leben?

Wir sind verlassen wie Kinder und erfahren wie alte Leute, wir sind roh und traurig und oberflächlich - ich glaube, wir sind verloren ${ }^{17}$ (Remarque 1974: 116).

Hay un pasaje de la novela de Remarque (1974: 158-159) que muestra de modo ejemplar la transformación personal que llevan aparejados los conflictos bélicos. El protagonista regresa a su casa aprovechando un permiso otorgado por los superiores de su batallón y, mientras observa la que durante años fue su habitación en la casa

16 “Compañero, no quería matarte. Si volvieras a estar aquí, no lo haría, siempre y cuando tú también fueras razonable. [...] Ahora me doy cuenta de que tú eres un hombre como yo. He pensado en tus granadas de mano, en tu bayoneta, en todas tus armas... Ahora veo a tu mujer y tu rostro, lo que tenemos en común. ¡Perdóname, compañero! ¿Cómo podías ser mi enemigo? Si tiráramos las armas y los uniformes, podrías ser mi hermano [...] Si salgo de ésta, compañero, lucharé contra todo esto que nos ha destrozado a los dos. A ti, la vida... ¿Y a mí? La vida también” (REMARQUE 2005: 201 y 203).

17 "Hoy pasaríamos por el paisaje de nuestra juventud como viajeros. Los hechos nos han consumido, conocemos las diferencias como comerciantes y las necesidades como carniceros. Ya no somos despreocupados, somos terriblemente indiferentes. Estaríamos allí, pero ¿viviríamos? Estamos abandonados como niños y somos experimentados como ancianos. Somos groseros, tristes, superficiales... Creo que estamos perdidos" (REMARQUE 2005: 116). 
familiar, descubre que prácticamente nada queda en él de aquel que fue antes de partir al frente. La guerra le ha convertido en un ser diferente, capacitado para observar su pasado como si fuera algo completamente ajeno a él:

Das Zimmer soll sprechen, es soll mich einfangen und tragen, ich will fühlen, daß ich hierhergehöre, damit ich weiß, wenn ich wieder and die Front gehe: Der Krieg versinkt und ertrinkt, wenn die Welle der Heimkehr kommt, er ist vorüber, er zerfrißt uns nicht, er hat keine andere Macht über uns als nur die äußere! [...].

Ein fürchterliches Gefühl der Fremde steigt plötzlich in mir hoch. Ich kann nicht zurückfinden, ich bin ausgeschlossen; so sehr ich auch bitte und mich anstrenge, nichts bewegt sich, teilnahmslos und traurig sitze ich wie ein Verurteilter da, und die Vergangenheit wendet sich $\mathrm{ab}^{18}$.

La consideración de la guerra como un acontecimiento traumático y crucial en el desarrollo de los individuos fue también puesta de manifiesto en Sin novedad en el frente al mostrar la imposibilidad del narrador y personaje principal de olvidar lo experimentado entre las trincheras -tema del que Remarque se ocupó en sus novelas El camino de vuelta y Tres camaradas-. Así se expresa en un diálogo de la obra en el que varios personajes imaginan cómo será su vida cuando regresen al hogar y dejen el frente. Mientras que uno de ellos señala lo problemático que resultará para todos ellos adaptarse a la vida cotidiana después de la guerra, otro afirma: "Zwei Jahre Schießen und Handgranaten das kann man doch nicht ausziehen wie einen Strumpf nachher" ${ }^{19}$ (Remarque 1974: 84).

En Imán, el poder perturbador del ambiente militar sobre el individuo queda evidenciado a través del tratamiento que se da a Viance, su personaje principal, cuya evolución demuestra el proceso de aniquilación sufrido por efecto del opresivo contexto bélico. Es la suya una personalidad destruida que sólo en el odio parece encontrar un sentido a la vida. Cumplimentando la famosa sentencia que afirma que "la violencia engendra violencia", la guerra transforma de forma radical al protagonista de Imán hasta hacer de él "una ruina, [...] un pelele, un tío ya exprimido" (Sender 1998: 298):

Viance $[\ldots]$ no es el mismo. Es el hombre que podía ser, quizá el que fue. Pero no. Viance no fue nunca así. Ahora se inquieta por las cosas nimias y próximas y esa es una de las razones por las cuales se desconoce a veces cuando piensa en años anteriores, serenos y audaces (Sender 1998: 49).

18 "Quiero sentir que pertenezco a esta casa, quiero escuchar su voz para saber, cuando vuelva al frente, que la dulce ola del regreso ahoga la guerra; ya ha quedado atrás, ya no nos carcome, no tiene más poder sobre nosotros que el puramente externo [...] De pronto surge ante mí un terrible sentimiento de extrañeza. No puedo encontrar el pasado. Me rechaza. Es inútil que implore y me esfuerce. Nada vibra. Indiferente y triste, estoy aquí sentado como un réprobo mientras el pasado me da la espalda" (REMARQUE 2005: 159).

19 "Dos años de disparos y bombas..., no podemos quitárnoslos de encima como si fueran unos calcetines" (REMARQUE 2005: 85). 
El trauma que supone la guerra viene motivado, entre otras razones, por poner a los soldados en contacto con un panorama dantesco y aterrador marcado por la violencia generalizada, la intensidad de las batallas y la tensión de la vida en las trincheras. Semejante situación provoca la conversión de los hombres en maquinarías de destrucción, en seres sólo preocupados por su supervivencia a los que lo único que les interesa es salvar su vida y acabar con la del enemigo, tal y como expone el narrador de la novela de Remarque:

Aus uns sind gefährliche Tiere geworden. Wir kämpfen nicht, wir verteidigen uns vor der Vernichtung. Wir schleudern die Granaten nicht gegen Menschen, was wissen wir im Augenblick davon, dort hetzt mit Händen und Helmen der Tod hinter uns her, wir können ihm seit drei Tagen zum ersten Male ins Gesicht sehen, wir können uns seit drei Tagen zum ersten Male wehren gegen ihn, wir haben eine wahnsinnige Wut, wir liegen nicht mehr ohnmächtig wartend auf dem Schafort, wir können zerstören und töten, um uns zu retten [...] Käme dein Vater mit denen drüben, du würdest nicht zaudern, ihm die Granate gegen die Brust zu werfen! ${ }^{20}$ (Remarque 1974: 107-108).

La degradación a la que se ve sometido el ser humano se intensifica con la pérdida de individualidad que producen la vida militar y el contexto bélico, en el que un soldado parece perder su condición de hombre individual y concreto para pasar a ser un simple número, un mero eslabón funcional en un engranaje dedicado a la destrucción. De este modo, la vida militar es puesta en cuestión también por la violencia que lleva aparejada y por el efecto que produce en los soldados, convertidos en el ejército en organismos inertes incapaces de sentir estímulo alguno más allá de los relacionados con la satisfacción de sus necesidades primarias y con la tensión del combate. Son seres cuya libertad individual está continuamente puesta en entredicho, al tener que integrarse en un grupo social en el que la esencia personal queda diluida al ser sometida a un intenso proceso de uniformidad. La alienación llega al extremo de acabar con la propia personalidad -"nada eres" (Sender 2001: 32), le dicen a Viance en un diálogo de Imán - y hacer que la vida sólo tenga sentido inmersa en las estructuras militares. Los soldados son parte de una maquinaría y, como tal, son iguales e intercambiables. Por eso la peripecia vital de uno de ellos en el ejército puede adaptarse sin problemas a las de los demás.

20 "Nos hemos convertido en animales peligrosos. No luchamos, nos defendemos contra la destrucción. No lanzamos las granadas contra los hombres, qué sabemos nosotros de eso en ese instante, la muerte nos acosa con manos y cascos, por primera vez en tres días podemos mirarla a la cara; por primera vez en tres días podemos defendernos de ella, nos posee una furia inmensa; ya no tenemos que esperar, impotentes, sobre el patíbulo; podemos destruir y matar para salvarnos. [...] Si tu propio padre viniera con los de enfrente, no dudarías en lanzarle una granada al pecho" (REMARQUE 2005: 108). 


\section{El horror bélico}

Los cambios que experimentan los combatientes en el frente pueden asimilarse a un proceso por el cual pierden las señas de identidad esenciales de la especie humana. Al exponer semejante transformación se denuncia el carácter inhumano de la guerra, capaz de modificar a todo aquel que se ve inmerso en ella. Además de por las lógicas consecuencias que se derivan de experimentar sensaciones de extrema intensidad como las provocadas por el combate y el contacto directo con la muerte, el dolor y la destrucción, el cambio viene generado por las características contextuales de los escenarios bélicos. Vivir en unas condiciones infrahumanas, más propias de animales que de personas, y en constante convivencia con la muerte, resulta una experiencia tan degradante como impropia de humanos.

El proceso de deshumanización es expuesto en estas novelas de guerra a través de varios procedimientos. Uno de ellos es el de la continua comparación de los soldados con animales y bestias $^{21}$ por la progresiva limitación de sus preocupaciones a la satisfacción de sus necesidades primeras -"dem Soldaten ist sein Magen und seine Verdauung ein vertrauteres Gebiet als jedem anderen Menschen" (Remarque 1974: 13) ${ }^{22}$ - y por la brutal gratuidad con la que emplea la violencia. "Gefährliche Tiere" (Remarque 1974: 107) o "Tiere im Kampf"23 (Remarque 1974: 131) son algunas de las expresiones que utiliza el narrador homodiegético de la obra de Remarque para definirse.

La progresiva similitud que los soldados adquieren con los animales se manifiesta en Imán a través de expresiones que comparan a los combatientes con "mulos" (Sender 1998: 272). La potencia de esta identificación se ve incrementada por el salvaje comportamiento al que inducía el contexto bélico en el que se encontraban, caracterizado por la paralizante abulia de la vida en las trincheras, la pérdida de valor de la vida, la constante presencia de la muerte y el desarrollo de acciones tan violentas como irracionales. En la novela de Sender hay, de hecho,

${ }^{21}$ El uso de la metáfora zoomorfa es frecuente en el léxico de todas las lenguas. Del mismo modo, reflexionar sobre el mundo y sobre el hombre partiendo de sus relaciones con el mundo animal ha sido la base de legendarios textos literarios como las fábulas o los bestiarios, pues, según Isabel ECHEVARRÍA (2003), "el animal forma parte del universo imaginario y literario del hombre, le permite la interpretación [...] del sentido de su existencia". De las diferentes identificaciones que pueden establecerse entre el orden humano y el zoológico -situadas en un amplio espectro dependiente de la metáfora estructural "las personas son animales"-, aparecen comúnmente en la literatura bélica las que perfilan en cada persona a un animal salvaje que acostumbra a estar reprimido y que sólo determinados contextos de tensión hacen surgir -la denominación de "bestias" y "chacales" a los soldados se insertarían en este grupo- y, por otro lado, las que identifican la relación entre los seres humanos con la estructura de dominación del mundo animal -como, por ejemplo, el uso de la palabra "rebaño" para referirse a los grupos de combatientes.

22 "Al soldado, su estómago y su digestión le resultan terreno más familiar que a cualquier otra persona" (REMARQUE 2005: 15).

23 “Animales peligrosos" (REMARQue 2005: 107); "Bestias en la batalla” (RemArQue 2005: 130). 
una meditación sobre la condición humana. Al plantearse cuáles son los límites del comportamiento, así como de la capacidad de supervivencia personal a determinadas situaciones, Imán adquiere una dimensión existencialista. Según Juan Luis Alborg (1962: 26-27), hay en la novela una constante preocupación por los valores humanos que conduce a una sensación de angustia similar a la que ofrecen los libros de autores como Albert Camus. De hecho, Olstad (1977: 135) ha llegado a interpretar la novela como "a protest against injustice, against the brutalization of some men at the hands of others".

La opresión del ambiente en el que han de vivir -o, más exactamente, sobrevivir- los personajes, reflejo de la sentida por los autores y de sus compañeros de ejército, tiene como consecuencia su degradación. La guerra envejece y embrutece a sus participantes de tal modo que, inmersos en un panorama de destrucción, llegan a ser identificados con animales y seres alejados de la esencia humana. Como ha señalado Fulgencio Castañar (1992: 143-144) en su análisis de la Guerra de Marruecos como tema narrativo, "la lenta aniquilación de la personalidad del individuo se produce casi paralela a una modificación de la apariencia física, pues al tiempo que crecen barbas y melenas hay un destrozo psíquico". Además de la transformación física, en Imán se insiste en el cambio cultural que sufren los soldados, obligados a experimentar situaciones irracionales totalmente alejadas de la lógica del comportamiento humano:

Te digo que comerse una rata o tragarse un par de moscas no tiene importancia para la salud. Todos lo días, al tomar el café, llegan dos o tres moscas y se ponen palmas revoloteando dentro del plato. Si al tercer manotazo no se van, les busco la vuelta y de pronto, iplaf!, cucharazo. Las capuzo dentro, se ahogan en el café y se joden. Todo es química. Nada tiene ningún bicho que no lo tengamos ya nosotros en los tejidos en los huesos. [...] Yo he bebido orines. Creo que los sargentos y los oficiales los beben con azúcar porque ha quedado bastante en el depósito de cadáveres. Están muy agrios, pero quitan la sed (Sender 1998: 60 y 121).

La descripción de la cotidianeidad de los hombres en el frente resulta casi inverosímil, a pesar de los recursos analógicos y del aséptico realismo empleado por los autores. Como ha mostrado Marcelino C. Peñuelas (1998: 9), "la aparente distorsión demencial de lo narrado, a fuerza de intensidad realista, es la misma distorsión que las cosas adquieren en la mente cuando lo horrendo alcanza los límites de la resistencia humana". El problema no reside en que se hayan de transmitir unas experiencias susceptibles de ser inimaginables para los lectores, sino en que incluso para quienes han sido testigos de ellas y han de narrarlas resultan inconcebibles. De ahí que Ramón J. Sender (1998: 154) recurra a modelos como el del Apocalipsis, identificable pero irreal, para intentar dar cuenta de los niveles de horror y dramatismo que le tocó vivir durante su estancia en el frente marroquí: 
La llanura pertenece a un planeta que no es el nuestro, un planeta muerto, aniquilado por las furias de un Apocalipsis. Silencio y muerte infinitos, sin horizontes, prolongados en el tiempo y en el espacio hasta el origen y el fin más remotos. La tierra, blanca; los arbustos, escasos y secos, llanura cruzada por mil caminos invisibles de desolación. Moros muertos, españoles despedazados.

\section{Conclusión: dos obras universales}

Gestadas en diferentes culturas y tradiciones lingüísticas, Sin novedad en el frente e Imán comparten, tal y como se ha ido desgranando a lo largo de este artículo, su intención de convertirse en testimonio de una situación cruenta y dramática como la guerra. A pesar de referirse a diferentes conflictos bélicos, ambas obras coinciden en su intención de vertebrar, a través de la experiencia personal y de la recurrencia de algunos de los tópicos temáticos y formales expuestos en estas páginas, un mensaje antibelicista capaz de combatir el militarismo y la defensa de la acción armada como forma de resolución de los problemas. Son, por tanto, ejemplos que demuestran cómo en ocasiones la literatura puede trascender el valor estético y artístico para dotar a su mensaje de una ejemplaridad ética de dimensiones universales. En la actualidad, casi un siglo después de que los dos libros fueran escritos, su mensaje sigue teniendo validez, pues ha sido capaz de obviar los condicionamientos contextuales en los que fue creado y de convertirse en un alegato contra la guerra, contra cualquier guerra.

\section{Referencias bibliográficas}

AguAdo, T., «Imán, La ruta y El blocao: memoria e historia del desastre de Annual», Revista hispánica moderna 57 (2004), 99-120.

AlberCA, M., «¿Es literario el género autobiográfico?», en: PozUelo Yvancos, J. M. y GómeZ, F. V. (eds.), Mundos de Ficción. Actas del VI Congreso Internacional de A.E.S. Murcia: Universidad de Murcia 1996, 175-183.

AlBerCA, M., «En las fronteras de la autobiografía», en: LedESMA PEDRAZ, M. (coord.), Escritura autobiográfica y géneros literarios. Jaén: Universidad de Jaén 1999, 53-76.

AlBERCA, M., El pacto ambiguo: de la novela autobiográfica a la autoficción. Madrid: Biblioteca Nueva 2007.

AlbORG, J. L., Hora actual de la novela española. Madrid: Taurus 1962.

AYALA, F., El escritor en la sociedad de masas. Buenos Aires: Sur 1958.

CARRASCO, A. M., La novela colonial hispanoafricana. Las colonias africanas de España a través de la historia de la novela. Madrid: Casa de África 2000.

CASTAÑAR, F., El compromiso en la novela de la II República Española. Madrid: Siglo XXI 1992.

CATELLI, N., El espacio autobiográfico. Barcelona: Lumen 1991.

ECHEVARRÍA, I., «Acerca del vocabulario español de la animalización humana», Círculo de lingüística aplicada a la comunicación 15 (2007) [http://www.ucm.es/info/circulo/].

Gomis, L., Teoría del periodismo. Cómo se construye el presente. Barcelona: Paidós 1991. 
HERNÁNDEZ, F. J., «La autobiografía en la literatura francesa, un género de nuestro tiempo», en: LEDESMA PEDRAZ, M. (coord.), Escritura autobiográfica y géneros literarios. Jaén: Universidad de Jaén 1999, 77-84.

HERNÁNDEZ, I. y MALDONADO, M., Literatura alemana. Épocas y movimientos desde los orígenes hasta nuestros dias. Madrid: Alianza 2003.

KoHan, S., De la autobiografia a la ficción. Entre la escritura autobiográfica y la novela. Barcelona: Grafein 2000.

LEJEUNE, P., «El pacto autobiográfico, veinticinco años después», en: HERMOSILLA Álvarez. M. A. y FernÁNDEZ PRIETO, C. (eds.), Autobiografía en España, un balance: actas del Congreso Internacional celebrado en la Facultad de Filosofía y Letras de Córdoba del 25 al 27 de octubre de 2001. Madrid: Visor 2004, 159-172.

MARTíNEZ GARRIDO, E., «Algunos aspectos de la especularidad narrativa: la identificación en la identificación, la literatura en la literatura», Revista de filología románica 4 (1986), 271-280.

NiCOlÁs, C., «Autobiografía y ficción», en: Hermosilla Álvarez. M. A. y Fernández PRIETO, C. (eds.), Autobiografía en España, un balance: actas del Congreso Internacional celebrado en la Facultad de Filosofía y Letras de Córdoba del 25 al 27 de octubre de 2001. Madrid: Visor 2004, 507-532.

OlstaD, C., «Sender's Imán and Remarque's All Quiet on the Western front», Revista de estudios hispánicos. Universidad de Alabama 1 - XI (1977), 133-140

PEÑUELAS, M. C. «Introducción», en: SENDER, R. J. Imán. Barcelonma: Destino 1998, 27-26.

ReMARQUe, E., Im Westen nichs Neues. Berlín: Kiepenheuer \& Witsch 1974.

REMARQUE, E., Sin novedad en el frente (trad. Judith Vilar). Barcelona: Edhasa 2005.

Romera CAStillo, J. N., La literatura como signo. Madrid: Playor 1981.

SENDER, R. J., Imán. Barcelona: Destino 1998.

STIERle, K., «¿Qué significa 'recepción’ en los textos de ficción?», en: MAYORAL, J. A., Estética de la recepción. Madrid: Arco Libros 1987, 87-144. 